\title{
Representation of Alcohol, Upbringing Style and Risky Alcoholism among Young Girls
}

\author{
YAO-Ackah Mathilde ${ }^{1}$ \\ OTEME Apolos Christophe ${ }^{1^{*}}$ \\ KOUAKOU Ossei ${ }^{1}$ \\ ${ }^{1}$ Department of Psychology \\ University Félix Houphouët-Boigny \\ Abidjan-Côte d'Ivoire \\ Corresponding author: otemeap@yahoo.fr, Tél: 0022547951613
}

\begin{abstract}
Next to alcoholism which usually prevails within the male population, a new phenomenon (risky alcoholism), as it is unusual, is gradually taking root among young girls. The importance of women in families and societies urges us to seek the responsible factors in order to try to reduce this scourge. Consequently, on the basis of their representation of alcohol and the type of family upbringing they received, the study proposes to explain young girls' risky alcoholism. In this respect, a sample of 120 girls from Abidjan is developed using empirical sampling by systematic variation. It is composed of 4 groups of equivalent subjects 2 to 2submitted to a questionnaire universally adopted by the World Health Organization, AUDIT-C (The Alcohol Use Disorders Identification Test Consumption). The data collected are processed using the Pearson Chi-square statistical test. This led to two results corroborating our views. Risky alcoholism is more prevalent among young girls who experience a permissive upbringing style and positively represent alcohol than those subject to a strict family upbringing and negatively representing alcohol.
\end{abstract}

Keywords: Risky alcoholism, social representation, upbringing style, young girls.

\section{Introduction}

The growing extent of young people's health damage behavior is more than alarming. The erroneous use of psycho-active substances mainly alcohol affects the individual and constitutes a burning issue in society. According to Cadet (2014) the repeated excess of alcohol is due to acts of violence, the search for "feats" at driving or violent sexual conducts.

For Grant et al. (2004), young people's consumption of alcohol increases and women's drinking is more and more comparable to that of men in United States. Young girls' style of alcoholism has shifted from non-consumption to risky alcoholism in Nigeria (Ibanga, 2005; Coleen and Gary, 2005). World Health Organization (WHO, 2006) argues that young girls' alcohol consumption is higher than that of their peers' young boys in Zambia. Seemingly, Côte d'Ivoire is not on the fringes of the phenomenon of female alcoholism.

Thus, it is important to carry out some researches in order to look into the factors liable to contribute to its expansion.

\section{I-Statement of The Thesis}

In traditional African societies, alcohol takes an important place in festivities, ritual ceremonies, conflicts resolutions and funerals. Women are generally kept out of this cultural beverage or ritual. These last decades, the change occurring in the traditional roles leads women to adopt drinking habits closer to those of men. Yet, in 1880s', through his reflections, Tarde introduces us in the less exploited fields of custom-alcoholism, stylealcoholism and deviance-alcoholism. He stressed the social influence and the decisive role of individual's attitudes and representation regarding the source of influence. The easy access to alcohol as well as the proliferation of spaces of alcoholism has allowed important shifts in alcohol consumption. 
An ingrain \& al notice that occasional and moderate alcohol consumption more and more gives path to regular and festive consumption of alcohol in France. This mass consumption of alcohol does not spare teenagers, young girls in particular. In Côte d'Ivoire, the survey of the Department of Health and Public Hygiene (Survey STEPS, 2005) has revealed that the percentage of alcohol consumption in 2004 is $81 \%$ for men and $60 \%$ for women. Besides, $77.9 \%$ of men and $22.1 \%$ of women consume 5 glasses or more at one occasion.

These figures show that in Côte d'Ivoire, as in the whole world, women and particularly young girls are not saved from the phenomenon of risky alcoholism. In their attempt to go from parental dependence relationships to those of reciprocities with others, teenagers experience risky behaviors related to tobacco, alcohol and even drug consumption.

In its recommendations for a low risk-consumption, the World Health Organization (WHO, 2002) warns that a standard glass of all kinds of alcoholic drink containing $10 \mathrm{~g}$ of pure alcohol brings about varied effects from sex to sex. This quantity boosts up the rate of alcohol to $0.20 \mathrm{~g} / \mathrm{l}$ in the blood of a man of $70 \mathrm{~kg}$ and $0.33 \mathrm{~g} / \mathrm{l}$ in that of $50 \mathrm{~kg}$ woman. Therefore, for a regular consumption, a woman must not drink more than two units of alcohol per day. As for man, he must not exceed three units per day. The consumer must spend at least one day per week without alcohol.

As for the occasional consumption, the quantity of alcohol must not exceed four units during only one occasion for men as well as women.

Risky alcoholism implies every punctual or regular conduct in which the consumption is superior to that indicated by WHO and not yet associated with medical damage, psychic or social/dependence, but liable to lead to that destruction at short, medium and long term. Alcohol damages women's brain easily. Once alcohol aemia of $0.5 \mathrm{~g} / \mathrm{l}$, we generally notice some alteration of behavior. Alcohol abuse causes harmful effects on alcoholics. It may lead a young girl to prostitution, debauchery, and the spreading of HIV/AIDS. All those things foster moral, social and physical degradation of alcoholics. However, its desinhibitor effects can sometimes be searched by teenagers.

According to Bègue (2013), alcohol consumption has an influence on self-perception. It may foster aggressive acts. The anti-social and ethylic conduct behavior offair-sex individuals provoke disapprobation which is much more important. It prompts to wonder as followed: how can we account for the propensity of alcohol abuse amongst young girls? Here is the core question of that research.

The previous studies contend that the responsible factors of alcoholism are naturally diverse. They are concerned with the groups of peers and family; and are of socio-economic, cultural, and also cognitive nature as Berglas (1987), Cerclés (2002) and Marton et al. (2001) put it.

An explanation of risky behavior is given by reasoned action theory (Fishbein and Ajzen, 1975). Based on that fact, we may argue that behavior is governed by social representation and environment norms. In other words, attitudes, norms, beliefs and intentions are in line with our behavior. Hence, any person's deed is determined by their intention to carry out that behavior. An intention is influenced by persons' attitude and by subjective norms related to behavior. Any attitude is about the assessment an individual makes of a wanted behavior. It is influenced by beliefs.

As a matter of fact, we may argue that young girls' attitudes regarding alcohol consumption, their appreciation and representation would be decisive in the growth of risky alcoholism. A positive representation would foster alcohol abuse. Indeed, the role of the cognitive processes in the adoption of some behavior of high-risk alcoholism is undeniable. Olds et al. (2005) maintains that beliefs concerning health influence the adoption of protecting behavior. Jodelet (1989) also tells us that individuals' representation governs their actions along with their way of handling the issues of health (Cerclé, 2002). That is why EROPP (2002) posits that beer and wine are perceived as inoffensive, harmless to health. This perception leads individuals to adopt some risky behavior regarding certain alcohol.

We can also consider that the ethylic conducts of teenagers would be determined by parental influences. So, the strict upbringing styles may be an obstacle to alcoholism.

In fact, families leave some sustainable and deep mark on their members' personalities, notably young people. Clearly, the familial factors as well as implemented upbringing styles are to be taken into account in the genesis and growth of children, in this case, young girls' behavior. 
Upbringing style is about the way parents apply educational strategies (Ricaud; Droisy et al., 2014). It is concerned with the way parents intervene in the relationship with their children.

Depending on whether the implemented style is authoritative, democratic or permissive, there will be varied effects on the growth of young people, their capacity of adaptation, their start of deviant activities, as Claes and Lacourre (2001) contend.

This fact is especially plausible in Côte d'Ivoire which is straddling tradition and modernity. And this specific context fosters a stricter traditional upbringing vis-à-vis young girls, especially because of the risks of unwanted pregnancies. Such a severe teaching centers on strictness and steadiness. In other words, it is strict as far as the implementation of constructive principles is concerned. It follows that a severe or rigid familial bringing up is likely to reduce the propensity of risky alcoholism. It may have been differently with a permissive or indifferent familial teaching. Indeed, this way of teaching prevails within some families of Côte d'Ivoire where western culture is highly assimilated (Touré, 1981). Such a profound acculturation inevitably leads to a deep upheaval in the relationships between parents and their offspring. More precisely, the acculturation prompts several Ivorian parents into granting their daughters a large freedom which leads those girls to profligacy. In so doing, the young girl falls in all kinds of vices namely high-risk alcoholism. And that risky alcoholism may be due to a permissive or indifferent upbringing style, which one follows from certain parents' renunciation under the yoke of a wrong interpretation of familial democracy that wrongly regards the supervision of assimilated children as a dragooning. Scientific literature supports that standpoint. Hence, Brody et al. (1999) state that the frustrating relationships between parents and children and the lenience of some parents lead children to risky behavior. Likewise, Jacob and Leonard (1994) consider that delinquent behavior, alcohol and other substances abuse amongst children sometimes derived from a lack of parenting affection, high criticism and hostility, but also from educational lenience and a lack of involvement in parenting practices. In such a climate, we can formulate the two following operational hypotheses:

Hypothesis 1: Young girls with a positive alcohol representation surrender to high-risk alcoholism whereas those whose representation of alcohol is negative undergo low-risk alcoholism.

Hypothesis 2: Young girls subject to a strict upbringing style experience low-risk alcoholism meanwhile their fellows under an indifferent or permissive teaching style witness high-risk alcoholism.

To test these hypotheses of research, we resort to a suitable quantitative approach or method. The reminder or justification of the selected procedures in this framework will help to judge the significance of the collected data.

\section{II-Methodology}

In this research, the implemented approach revolves around three points. So, we first lyanalyze variables, then sample and finally the material used for the collection of data

\section{1- Research variables}

Three qualitative variables derived from the aforementioned hypotheses. It is about two independent variables namely the representation of alcohol and upbringing style, and one dependent variable, that is, risky alcoholism conduct. The representation of alcohol signifies the image, the opinion and the idea young girls have of alcohol. This is perceived through positive representation (positive evaluation of alcohol) and negative representation of alcohol (depreciation of alcohol)

The upbringing style suggests or denotes the way teaching practices are implemented. This style is divided in strict and indifferent style. Parents of severe style are warm, and involved in the relationship with their offspring by controlling them. But, indifferent parent slack warmth, involvement and parental control. The considered dependent variable is risky alcoholism behavior. It is determined through AUDIT-C questionnaire (The Alcohol Disorders Identification-Consumption) which is an instrument universally certified and adopted by WHO. The instrument is used to measure the rate of subjects' alcoholism. It includes two modalities: low-risk and risky alcoholism. A score under 3, which is a mid-index of alcoholism for women according to Saunders et al. (1993), corresponds to low-risk alcoholism. However, beyond the threshold of 3, individuals are regarded as undergoing risky alcoholism. 


\section{2- Sampling}

Abidjan is the city of the current survey. As we know, this megalopolis is the melting pot of all social issues of the country. Its strong urbanization makes it a land of settlement. Likewise, Abidjan is mainly the business center of West African sub-region.

However, alcoholism is one of the burning social issues of the city inhabitants. The situation is all the more important because the spread of poverty causes the proliferation of "maquis" (restoration infrastructures) and bars in all neighborhoods throughout the district of Abidjan. The increase of alcohol consumption in these places results in the fact that young people are becoming alcoholics.

The sample of 120 subjects has been elaborated thanks to factorial plan of the quasi-experimental methods of sampling. It is made up of 4 groups of 2 to 2 reciprocal subjects:

- Young girls who are positive to alcohol and those who are negative to alcohol.

- Young girls experiencing a strict upbringing style and their peers dependent on an indifferent style.

Each group is made up of 60 subjects. Those subjects are Christians and about 18 years old. The young girls are also from under privileged socio-economic background and live at least with a biological parent. They are students of eleventh grade and attend public school in Abidjan.

\section{3- Material}

The instrument used for data collection is the questionnaire. It centered on three parts. The first part provides information about parasitic variables namely sex, educational level, age, religion, family structure, etc. The second part concerns the representation of alcohol. It refers to items relating to opinions and attitude towards alcohol. The third part underscores girls' alcoholism. It turns around the AUDIT-C (The Alcohol Disorders Identification Test Consumption) which is a short version of the AUDIT questionnaire (Saunders et al., 1993) developed by the World Health Organization and whose metrological properties are universally recognized.

The material is submitted from one individual to another among the secondary schools girls. Each respondent receives the questionnaire outside of class and fills in it straightaway for about ten minutes. In so doing, we think that the data collected can be reliable. And this gives credibility to the teaching they lead to.

\section{III- Results}

The findings of the study and their psychological significance are considered in relation to the initial working hypotheses. They are of two levels. One relates to the impact of alcohol representation on risky alcoholism and the other is linked to the relationship between alcohol and the experienced upbringing style.

\section{1- High-risk Alcoholism in accordance with the Representation of Alcohol among}

\section{Young Girls}

The Pearson Chi Square statistical test is used to look into the impact of alcohol representation on risky alcoholism in girls' lives. It is applied to the data of the following table:

Table I: Frequencies of girls in accordance with the tendency to high-risk alcoholism and representation of alcohol

\begin{tabular}{llll}
\hline Representation of Alcohol & High-risk Alcoholism & Low-risk Alcoholism & Total \\
\hline Positive Representation & 38 & 22 & 60 \\
Negative Representation & 10 & 50 & 60 \\
Total & 48 & 72 & 120 \\
\hline
\end{tabular}

The Chi square test shows a value of 27.22. This result is significant regarding the threshold probability of .002. It proves that the two groups in comparison are different from each other. An examination of the preceding table proportions sheds light on this difference. In this respect, a large majority of girls who represent alcohol positively undergo risky alcoholism ( $63.33 \%$ or 38 out of 60 subjects) while a minority of them experiences low-risk alcoholism (36.67\% or 22 out of 60 subjects). Conversely, few $16.67 \%$ (10 out of 60 subjects) who have a low opinion of alcohol indulge in risky alcoholism whereas most of them (83.33\% or 50 out of 60 subjects), face short-risk alcoholism. Consequently, the first hypothesis proves correct.

The girls whose representation of alcohol is positive come in to risky alcoholism while those having a negative thought are faced with short-risk alcoholism. 
The theory of reasoned action (see Statement of the Thesis) provides an explanation for this result in so far as it shows that behavior is determined by a favorable or unfavorable attitude. That is, intentions concerning a social phenomenon. The intention rests on two elements-of personal as well as social nature. As for the theory, it views individuals' behavior as dependent on a double influence: individuals' experiences and the social background stimuli.

As far as individuals are concerned, their behavior is influenced by the specific beliefs about a given phenomenon or situation. These influences may involve information or knowledge pertaining to a fact. As a result, the subject's assessment of this knowledge and the representation of facts guide his/her choices. Therefore, girls' positive or negative evaluation of alcohol will influence the choice. That is, the kind of attitude adopted in the face of alcoholism. In this way, the internalized representation will influence conducts.

Thus, teenage girls drinking much alcohol are those whose representation is positive. For instance, they think that alcohol helps to feel more at ease in group outings. Fur them, it also permits to increase self-confidence in front of the opposite sex people. Finally, according to the girls, alcohol allows escaping from worries and problems for a while. So, they argue that there is no harm if a girl consumes alcohol like a man.

The specific role of these cognitions (beliefs, expectations) vis-à-vis alcohol is to urge to risky alcoholic behavior. However, young girls who have negative representation will avoid high-risk drinking. For example, they believe that alcohol causes loss of self-control and lucidity. Besides, in their opinions, it leads to debauchery, but also is dangerous for health and women's well-being. Similarly, alcohol gives rise to sexual abuse and often brings about a decline of academic performance.

In this context, (Cadet, 2014) contends that the most important thing is the cognitions, that is to say, the beliefs and representations of an object and not the object properties. The representation is generally acquired by experience through the circle and advertising. They are internalized and guide the conduct. As a result, the value given or the assessment of the consequences peculiar to an object influences the conduct. Girls who are aware of the harmful consequences of alcohol and set great store by the information internalize them. They eventually hate alcohol. This kind of girls will tend to refrain from adopting risky drinking behavior. However, those who minimize the damaging effect and continue to praise alcoholic drinking; will have a tendency to indulge in highrisk alcoholism. This specific health damage behavior may seem distant and even improbable although the drinking pleasure is immediate. And this situation may therefore lead to lasting alcoholism.

\section{2- Type of Upbringing and Risky Alcoholism among Young Girls.}

The impact of upbringing type on risky alcoholism among the girls of the study is examined through the significance criterion of Pearson's Khi square. This test is applied to the data in the table below.

Table II: Distribution of Girls by Upbringing Style and Their Tendency to Risky Alcoholism

\begin{tabular}{llll}
\hline Type of Upbringing & Risky Alcoholism & Low-risk Alcoholism & Total \\
\hline Strict Upbringing & 20 & 40 & 60 \\
Indifferent Upbringing & 35 & 25 & 60 \\
Total & 55 & 65 & 120 \\
\hline
\end{tabular}

The Chi Square value calculated from the table above is 7.56. It is significant as far as the .01 probability level is concerned. The value consequently shows that there is a significant difference between the survey groups.

The comparison of the table frequencies permits to get the significance of that difference. In fact, $66.67 \%$ of girls (40 out of 60 subjects) submitted to a severe parental teaching experience a low-risk alcoholism while only $33.33 \%$ (20 out of 60 subjects), indulge in risky alcoholism.

The situation is quite different concerning girls facing indifferent upbringing style. Indeed, 58.33\% (35 out of 60 subjects) of these ones abandon themselves to dangerous alcoholism whereas a minority of them is concerned with short- risk alcoholism (41.67\% or 25 subjects out of 60 ).

This result is consistent with the working hypothesis. Indeed, the postulation maintains that young girls subject to a strict upbringing style will come to safer alcoholism while their fellows subjected to an indifferent teaching style give themselves to risky drinking. The finding is interpreted in the light of reasoned action theory (see Statement of the Thesis). From a social point of view, individuals' intention to choose a specific behavior depends on the subjective norms corresponding to their perception of the social pressure. 
Therefore, girls' choice of alcoholism status (safer/dangerous) is influenced by interactions with their group members, especially parents. In other words, these girls will seek their parents' approval by adapting their behavior to home environment standards. If these standards are strict and rejecting risky behavior, the intention vis-à-vis alcoholic beverages abuse will be unfavorable. But, in indifferent upbringing style families, the girls will tend to adopt dangerous behavior in the face of alcohol. For example, parents who do not care about their daughter's behavior will inadvertently encourage negative behavior such as alcoholism. Under such circumstances, we can argue that subjective attitudes and norms influence the intention of alcohol abuse.

\section{IV-Discussion}

We started from the idea that unsafe alcoholism is dependent on socio-cognitive phenomena, particularly social representation and parental teaching practices. The results obtained confirm our hypotheses. In fact, perilous drinking is boosted up by a positive perception of alcohol and a permissive family upbringing style. These viewpoints are supported by other works. These ones underscore the impact of social representation and parents' care on children's negative or high-risk actions. In this way, Jodelet (1991) reports the interdependence between cognitive development and individuals' behavior. More specifically, people's social representation largely determines their risk-taking behavior (Jodelet, 1989). Our second result is corroborated by Maccoby and Martin (1983). Both consider that children do not learn how to respect rules within strong tolerance or permissive style. We can therefore expect them to abandon themselves to alcohol. Besides, Jacob and Leornard (1994) note that the emergence of antisocial behavior namely delinquency, alcohol and drug abuse, relationships with deviant peers and so on largely depends on parents.

Vouillot (1986), finds a more restrictive and rigid bringing up for girls.

However, we must be careful not to consider that only the upbringing style impact influences the fair-sex drinking. Some other authors report that factors such as a late experience of loneliness and home environment subject to early alcoholism are also likely to determine this phenomenon (Cerclé, 2002). It goes without saying that the systematic study of female unsafe alcoholism must continue in order to stabilize results or to come to a general belief.

\section{Conclusion}

This study focuses on the influence of cognitive processes on drinking behavior. It highlights the role of social representation on risky alcoholism in adolescent girls' lives. Alcohol increases vulnerability. And its abuse by already-vulnerable girls appeals to us all the more because girls are very often submitted to disapproval when they indulge in this kind of practices. Identifying the factors that boost up the conduct helps to direct solution research concerning the new phenomenon of female unsafe alcoholism. Beliefs (cognitions) are crucial in behavior adoption. So, acting on them would prevent risky conduct. A sensitization of young people about alcohol damage in school and family environment can help to raise awareness about the harmful effects of alcoholic drinking.

However, we contend as Weinman and Figueiras (2002) point out that early health promotion research found that lack of information was the main reason for the lack of interest in health behavior. It is undeniable that the information conveyed during the sensitization campaigns leads to persuasive communication. They are likely to affect the power of beliefs and risk evaluation. The information encourages the subject to wonder: is such a negative behavior acceptable, is it worth adopting?

Thus, awareness-raising campaigns undertaken in the framework of persuasive communication can "disrupt" or "correct" certain positive cognitive development or the subject's promotion of alcohol. This may urge the individual to adopt healthier representation by highlighting harm and danger of alcohol. The subjects would then become aware of the gravity of what they risk by giving themselves to immediate pleasure. In this way, they will refrain themselves from carrying out the described negative act, that is, high-risk alcoholism.

In addition to active sensitizations related to persuasive communication, strong family-oriented actions can also discourage girls' tendency to risky alcoholism.

Nowadays, the entry of democracy into all spheres of human existence encourages many parents to practice permissive teaching or adopt an indifferent upbringing style. They then come to a renunciation concerning their responsibility vis-à-vis their offspring. Consequently, these ones get the opportunity to give their ideas free rein. The same goes for the satisfaction of their desire including the most perverse. The permissive submitted young adopt socially reprehensible behavior too. 
In this way, the girl who wants to give herself to dangerous alcoholism or to remain within it meets with no opposition or parental condemnation. The permissiveness or indifference of her parents gives her a discreet encouragement.

In so doing, a relatively weak superego which is then formed in the girl leaves the feelings even negative ones to appear to consciousness for materialization. Social realities seem to be abolished and the reality principle fades in the face of primary desires power.

It is therefore desirable for social, state or private institutions to develop the "parents' school". This will train parents to fully play their family roles. The institutions can help them correct the inadequacies or excesses of their bringing up practices. In so doing, parents will provide their children with a strong personality for a harmonious development of their beings. The destiny of the latter depends on it insofar as the Ivorian society undergoes the blurred boundaries between acculturation by Western values and an attachment to the African tradition. This situation exposes most Ivorians to a clear lack of socio-cultural references.

\section{References}

Aigrain, P., Boulet, D., Lalanne, J-B, Laporte, J-P., Melani, C. (2000). La consommation de vin en France. Premiers résultats de l'enquête 2000. Paris, ONIVINSINFOS.

Bègue, L. (2013). Agression. In L. Bègue et O. Desrichard : Traité de psychologie Sociale. Louvain-La-Neuve, de Boeck.

Cadet, B. (2014). Le traitement des conduites à risque dans le champ de la santé et de la maladie. In G-N. Fischer et C. Tarquino. Psychologie de la santé. Applications et interventions. Paris, Dunod.

Cerclé, A. (2002). L'approche interactionniste et développement des facteurs de risque étiologiques l'exemple de l'alcool. In G.N. Fischer. Traité de Psychologie de la Santé. Paris, Dunod.

Cerclé, A., Somat, A. (2005). Psychologie Sociale Cours et exercices. $2^{\mathrm{e}}$ édition. Paris, Dunod.

Claes, M., Lacourse, E. (2001). Pratiques parentales et comportements déviants à l'adolescence. Enfance, 4 : 379-399.

Collen, A. D., Gary, R. (2005). Le point sur la recherche. Consommation d'alcool et grossesse : Une importante question sociale et de santé publique au Canada. Ottawa, Agence de la Santé Publique au Canada.

Enquête STEPS (2005). Les facteurs de risque des maladies chroniques dans les régions sanitaires des lagunes (Côte d'Ivoire).Document. Abidjan, Ministère de la Santé et de l'Hygiène Publique.

Eropp (2002). Les hommes et l'alcool. In F. Beck, S. Legleye, P. Periti - Watel. Penser les drogues : Perception des produits et des politiques publiques. Editions Prison - Roche.

Fischbein, M.M \& Ajzen, I. (1975). Belief, altitude, intention behaviour : an introduction to théories and research. MA, Addison Wesley.

Grant, B.F; Dawson, D.A., Stinson, F.S. Chou, S.P. Dufour, M.C., Piickering, R.P (2004). The 12 months prevalence and trends in DSM IV alcohol abuse and dependance: United States 1991-1992 and 2001-2002. Drug alcohol and dependance. 74(3), 223-234.

Ibanga, A. (2005). The contexts of alcohol consumption by men and women in Nigeria. In I. Gbot; R. Room : Alcohol, gender and drinking problems : perspectives from low and middle income countries. Genève, Organisation Mondiale de la Santé.

Jacob, T. \& Leonard, K. (1994).Family and peer influences inthe development. In R. Zucker, G. Boyd, J. Howard (éds). The development of alcohol problems: exploring the biopsychosical matrix of risk. Research monograph, $\mathrm{n}^{\circ} 26, \mathrm{US}$ Department of Health and Human Services.

Jodelet, D. (1989). Les représentations sociales. Parsis, Presses Universitaires de France.

Maccoby, E.E. \& Martin, J.A. (1983). Socialization in the context of the family: Parent-child interaction. In E.M. Hetherington (dir.). Handbook of child Psychology: Socialization, personality and Social development. New York, Wiley.

OMS. (2006). Consultation technique de l'organisation Mondiale de la Santé sur les problèmes de santé publique provoqués par l'usage nocif de l'alcool dans la région africaine. Genève, Organisation Mondiale de la Santé.

Perchec, C. \& Claes, M. (2012). Que peuvent faire les parents pour promouvoir l'ajustement psychosocial de l'adolescent ? Enfance, 3, 329-344.

Ricaud - Droisy, H., Oubrayie - Roussel, N., Safont - Mottau, C. (2014). Psychologie du développement. Enfance et adolescence. Paris, Dunod.

Saunders, J.B., Aasland, O.G., Ba Bor, T.F., De La Fuente, J.R. \& Grant, M. (1993). Development of the Alcohol Use Disorders Identification Test (AUDIT) : who collaborative project on early detection of persons with harmful alcohol consumption - II. Addiction, 88 (6), 791-804.

Touré, A. (1981). La civilisation quotidienne en Côte d'Ivoire. Procès d'occidentalisation. Karthala.

Vouillot, F. (1986). Structuration des pratiques éducatives parentales selon le sexe et l'enfant. Enfance, 39 (4), 351-366.

Weinman, J. \& Figueiras, M.J. (2002). La perception de la santé et de la maladie. In G-N. Fischer : Traité de psychologie de la santé. Paris, Dunod. 